\title{
The changing carbon cycle of the coastal ocean
}

\author{
James E. Bauer ${ }^{1}$, Wei-Jun Cai ${ }^{2}$, Peter A. Raymond ${ }^{3}$, Thomas S. Bianchi ${ }^{4}$, Charles S. Hopkinson ${ }^{5}$ \& Pierre A. G. Regnier ${ }^{6}$
}

The carbon cycle of the coastal ocean is a dynamic component of the global carbon budget. But the diverse sources and sinks of carbon and their complex interactions in these waters remain poorly understood. Here we discuss the sources, exchanges and fates of carbon in the coastal ocean and how anthropogenic activities have altered the carbon cycle. Recent evidence suggests that the coastal ocean may have become a net sink for atmospheric carbon dioxide during post-industrial times. Continued human pressures in coastal zones will probably have an important impact on the future evolution of the coastal ocean's carbon budget.

$\mathrm{T}$ The coastal ocean consists of several distinct but tightly connected ecosystems that include rivers, estuaries, tidal wetlands and the continental shelf. Carbon cycling in the coastal waters that connect terrestrial with oceanic systems is acknowledged to be a major component of global carbon cycles and budgets ${ }^{1-3}$. Carbon fluxes within and between coastal subsystems, and their alteration by climate and anthropogenic changes, are substantial. It is therefore essential to understand, and accurately account for, the factors regulating these fluxes and how they affect the ocean and global carbon budgets.

Although the coastal contribution to the anthropogenic carbondioxide budget was neglected in past assessments reported by the Intergovernmental Panel on Climate Change (IPCC) and others, it has been recognized recently ${ }^{3-5}$. Constraining the exchanges and fates of different forms of carbon in coastal settings has been challenging and is so far incomplete, due to the difficulty in scaling up relatively few observational studies. Rapid expansion of organic and inorganic carbon data collection (especially on the partial pressure of $\mathrm{CO}_{2}, p_{\mathrm{CO}_{2}}$ ) in coastal waters over the past decade, as well as new biogeochemical contexts for coastal systems dynamics, make this an exciting time for the field. A new generation of coupled hydrodynamic biogeochemical models can now mechanistically incorporate the factors that control carbon dynamics, such as elemental stoichiometry and biological turnover of both internally and externally supplied organic matter and nutrients, and their inputs and residence times ${ }^{6-8}$. These new tools will provide a more predictive understanding of how coastal systems respond to human impacts and climate perturbations.

In this Review, we discuss our current understanding of the sources, fates and exchanges of organic and inorganic carbon in the coastal ocean, with an emphasis on the factors that contribute to net carbon fluxes within and between coastal subsystems. Carbon inputs and transformations are considered in the contexts of net air-water exchanges of $\mathrm{CO}_{2}$, carbon burial in coastal subsystems, and exports to the open ocean. We explicitly address the growing recognition of how the coastal carbon cycle has fundamentally shifted in recent years owing to a variety of human activities. This synthesis shows that the present-day coastal ocean is a net sink for atmospheric $\mathrm{CO}_{2}$ and a burial site for organic and inorganic carbon, and represents an important global zone of carbon transformation and sequestration. The purported shift of the coastal ocean from a $\mathrm{CO}_{2}$ source to a $\mathrm{CO}_{2}$ sink over the past 50 to 100 years also has ramifications for its future role in the ocean and global carbon cycles.

\section{Riverine carbon inputs to coastal systems}

Riverine supply of many elements, including carbon of largely terrestrial origin, is important to the steady-state chemistry of the oceans (Fig. 1a). Although estimates of riverine fluxes of both organic carbon ${ }^{9-11}$ and inorganic carbon ${ }^{3,12}$ continue to be improved by new geospatial tools and by scaling and modelling approaches, these fluxes are not greatly different from earlier estimates ${ }^{13}$ (Fig. 2 and Box 1). Average annual carbon fluxes to all major ocean basins and seas are now available ${ }^{10,12}$. Fluxes are generally well correlated with river discharge, except in certain regions where factors such as high peat and carbonate coverage, and high erosion rates in watersheds also control carbon inputs ${ }^{10-14}$.

\section{Factors regulating riverine carbon fluxes}

Climate has long been recognized as an important driver of river carbon supply to the coastal ocean (Fig. 1a). Watersheds with high precipitation have higher riverine discharge rates, and studies have long documented a primary regulation of carbon fluxes by discharge ${ }^{13}$, owing to the importance of transport limitation. Temperature also regulates important abiotic and biotic processes that can alter water throughput, flow paths, dissolution rates and watershed carbon stocks. The net effect of temperature on carbon fluxes can therefore vary between regions and among the different organic and inorganic forms of carbon (for example, see refs 15 and 16) (Fig. 1a).

In addition to annual precipitation and temperature, it is now clear that hydrologic 'events', such as extreme rainfall from tropical storms, are disproportionately important to riverine organic carbon transport. The erosive power of these storms is responsible for most particulate organic carbon (POC) export from watersheds to the coastal ocean, especially in mountainous regions ${ }^{17}$. Increases in riverine dissolved organic carbon (DOC) concentrations - and, hence, in annual riverine DOC export to coastal systems - can also result from these events. For example, a single tropical storm can be responsible for more than $40 \%$ of average annual riverine DOC export ${ }^{18}$. On decadal time scales, single large flood events can export $80-90 \%$ of POC from mountainous regions ${ }^{17}$. Climate models suggest that although the change in storm frequency is difficult to predict, the most intense storms will probably become more frequent ${ }^{4}$, and this will consequently affect riverine DOC and POC transport to coastal waters.

We can currently estimate with moderate to high certainty the riverine transport of terrestrial carbon to the coastal ocean (Fig. 2 and

${ }^{1}$ Aquatic Biogeochemistry Laboratory, Department of Evolution, Ecology and Organismal Biology, The Ohio State University, Columbus, Ohio 43210, USA. ${ }^{2}$ School of Marine Science and Policy, University of Delaware, Newark, Delaware 19716, USA. ${ }^{3}$ School of Forestry and Environmental Studies, Yale University, New Haven, Connecticut 06511, USA. ${ }^{4}$ Department of Geological Sciences,

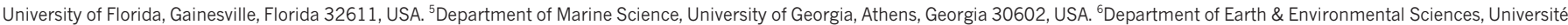
Libre de Bruxelles, Brussels 1050, Belgium. 


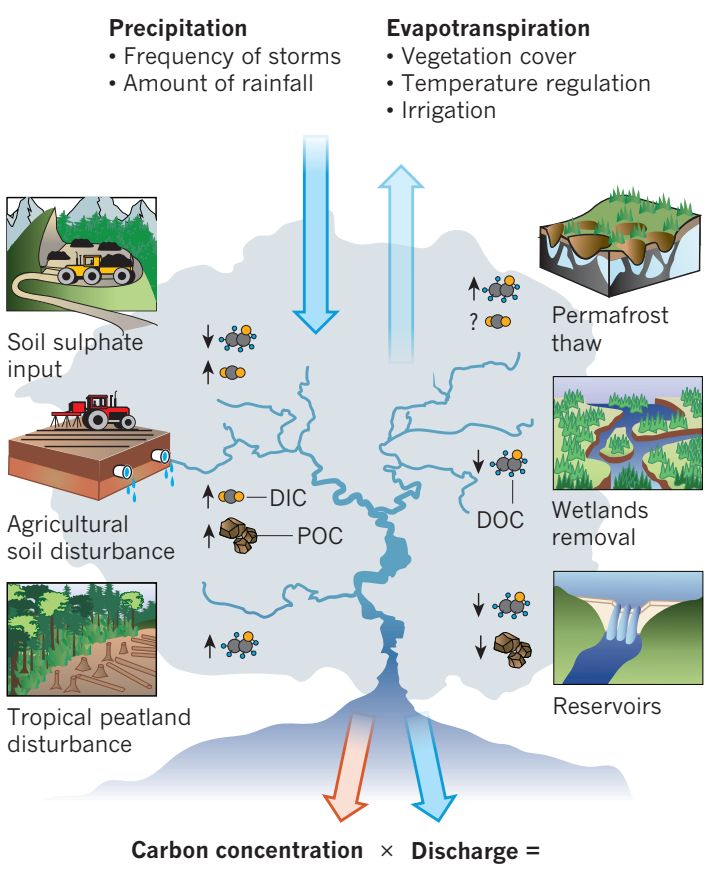

Carbon flux

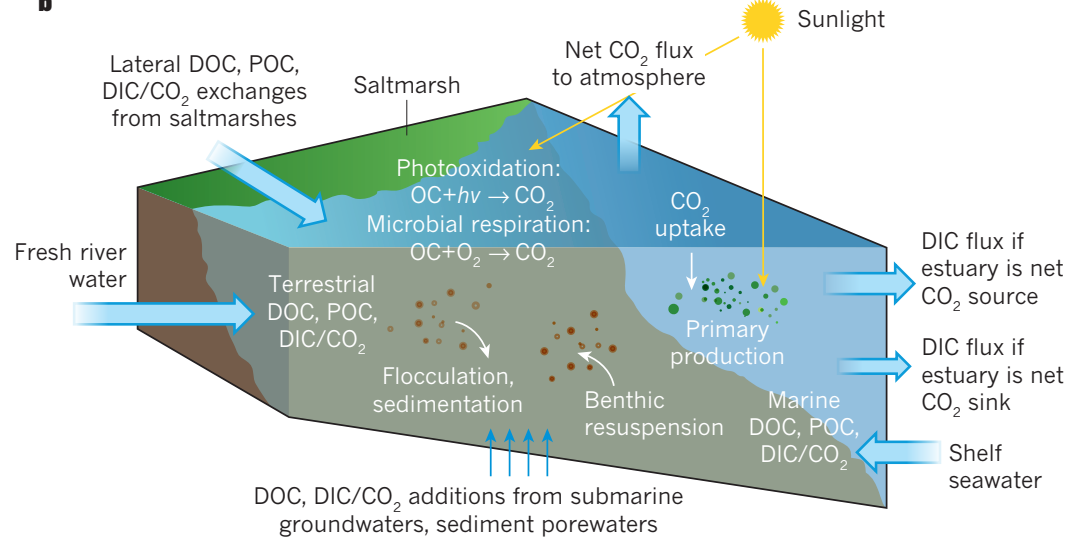

$\mathbf{c}$ Solar UV
irradiation
Low salinity
waters

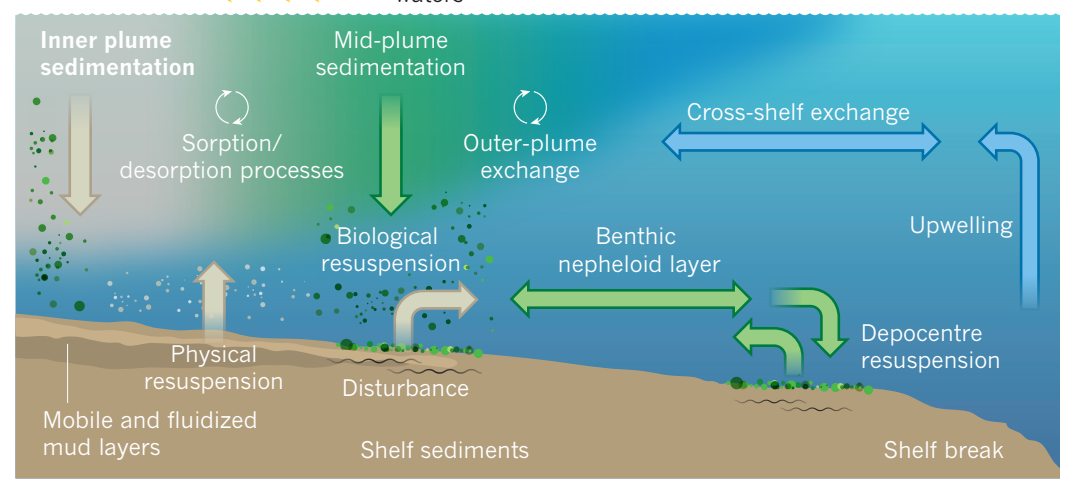

water (in which the salinity is zero), marine sources carried in shelf sea water (with a salinity of more than or equal to 30), and uniquely estuarine materials. Organic carbon is lost owing to salinity-induced flocculation, sedimentation, microbial respiration and photooxidation. Estuaries can modulate the export of carbon to the shelf depending on whether the estuary is a net carbon source or carbon sink. c, A representative continental shelf at its interface with a lowsalinity river or estuarine plume. Physical and biogeochemical processes control the source, transport and fate of organic carbon. Carbon is exchanged the interface between plume and shelf waters through sorption and desorption. Organic carbon transport to the open ocean is supplemented by physical resuspension, bioturbation and mobile and fluidized mud layers. The benthic nepheloid layer contains significant amounts of suspended sediment, which may be deposited to and resuspended from depocentres. Primary production in inner shelf waters may be limited by high sediment loads in plumes, whereas regions of upwelling in outer shelf waters can lead to elevated primary production. DOC, dissolved organic carbon; POC, particulate organic carbon; DIC, dissolved inorganic carbon.

most estuaries are geographically confined, estuaries of high-discharge rivers (for example, the Amazon) can extend onto, and even across, the continental shelf ${ }^{22}$. Numerous factors, such as the geomorphology of the estuary and the magnitude and stoichiometry of nutrient inputs (Box 3), control the fluxes and cycling of carbon in estuaries (Fig. 2). These important physicalbiogeochemical reactors greatly modify the amounts and characteristics of organic and inorganic carbon transported between land and the ocean ${ }^{2,23,24}$.

\section{Organic carbon in estuaries}

DOC and POC in estuaries are derived from terrestrial, marine and estuarine primary production (Fig. 1b). Owing to their unique biochemical and isotopic characteristics, specific sources of organic carbon have generally been easier to quantify than their fates within estuaries $^{23,24}$. In situ production of organic carbon in some estuarine waters can be significant to the coastal carbon budget because it can equal or exceed the river or marine supply ${ }^{25,26}$.

Mineral sorption and desorption and photochemical dissolution can lead to an interchange between DOC and POC in estuaries ${ }^{27,28}$. 
Estuaries also experience significant losses of organic carbon owing to the combined influences of microbial degradation and photochemical oxidation $^{29-31}$, scavenging, sedimentation, and salinity-induced flocculation of DOC and POC $^{32}$ (Fig. 1b). Individual sources of organic carbon have unique reactivity and residence times that affect their degradation ${ }^{6}$ to climatically important gases such as $\mathrm{CO}_{2}$, methane and volatile organic carbon in estuarine waters and sediments ${ }^{33}$, and their export to continental shelves. Estuaries can therefore modulate organic carbon exports to shelves relative to riverine organic carbon fluxes alone ${ }^{34}$.

Most estuaries have tremendous internal spatial and temporal heterogeneity in carbon processing and fluxes, making it difficult to quantify even a single estuary's net carbon balance. As a result, we lack the measurements from a representative number of systems for accurate global or even regional estimates of the direction and magnitude of net organic carbon fluxes that occur within estuaries. In addition, the complex interplay between organic carbon and both inorganic and organic nutrient inputs (Box 3) from land and ocean have an important, but poorly quantified, role in regulating the balance between net organic carbon production (autotrophy) and consumption (heterotrophy) in estuaries ${ }^{35,36}$. Process-based models of coupled estuarine hydrodynamics and biogeochemistry have recently addressed interactions between the organic and inorganic carbon cycles at the scale of individual estuaries (for example, see refs 8, 21, $35,37)$, but none are currently suitable for regional or global applications (Box 2).

\section{Estuarine carbon dioxide and inorganic carbon exchange}

$\mathrm{CO}_{2}$ emissions from European estuaries were recognized to be a significant component of the regional $\mathrm{CO}_{2}$ budget ${ }^{38}$ about 15 years ago. Subsequent studies estimated global estuarine $\mathrm{CO}_{2}$ emissions to be on the order of $0.2-0.4 \mathrm{PgCyr}^{-1}$ (refs 2, 33, 39, 40). Estuaries occupy a small portion of global ocean area (about $0.2 \%$ ), and, therefore, their $\mathrm{CO}_{2}$ emissions are a disproportionately large flux when compared with $\mathrm{CO}_{2}$ exchanges between the open ocean and atmosphere ${ }^{41}$ (Fig. 3a). However, the uncertainty in the global estuarine $\mathrm{CO}_{2}$ emission flux is high (Fig. 2, 3a,b and Box 1) due to very limited spatial and temporal coverage during field observations, large physical and biogeochemical variability and insufficient use of generalized hydrodynamic-biogeochemical models in estuaries $^{2,22}$.

In addition to very high $p_{\mathrm{CO}_{2}}$ and correspondingly high rates of $\mathrm{CO}_{2}$ degassing, dissolved inorganic carbon (DIC) is also usually enriched in estuarine waters and exported to continental shelf waters (Fig. 2). The elevated $p_{\mathrm{CO}_{2}}$ and DIC result from in situ net respiration of internally and externally supplied organic carbon and lateral transport of DIC from rivers and coastal wetlands $s^{2,33,40,42,43}$ and $\mathrm{CO}_{2}$-rich groundwaters ${ }^{44}$. Additionally, low-DIC estuaries ${ }^{42}$ generally experience higher $\mathrm{CO}_{2}$ degassing fluxes than high-DIC estuaries, as waters of the latter retain $\mathrm{CO}_{2}$ longer owing to their greater buffering capacity ${ }^{45,46}$.

\section{Exchanges with tidal wetlands}

Highly productive tidal wetlands flank many estuaries and laterally export both dissolved and particulate carbon to estuaries and coastal systems ${ }^{2,47}$. Regional and global estimates of wetland fluxes are hampered by a scarcity of reliable estimates of wetland surface area and studies of carbon export. The limited studies that are available suggest that wetlands act as a net source of carbon to estuaries that could be comparable with riverine carbon supply ${ }^{2,3}$ (Fig. 2). However, although some of the carbon exported from wetlands is recycled in estuaries, significant amounts are buried in estuarine sediments and exported to continental shelves (Fig. 2).

Globally, estuaries are net heterotrophic, meaning that respired organic carbon exceeds that supplied by rivers and wetlands, and produced in

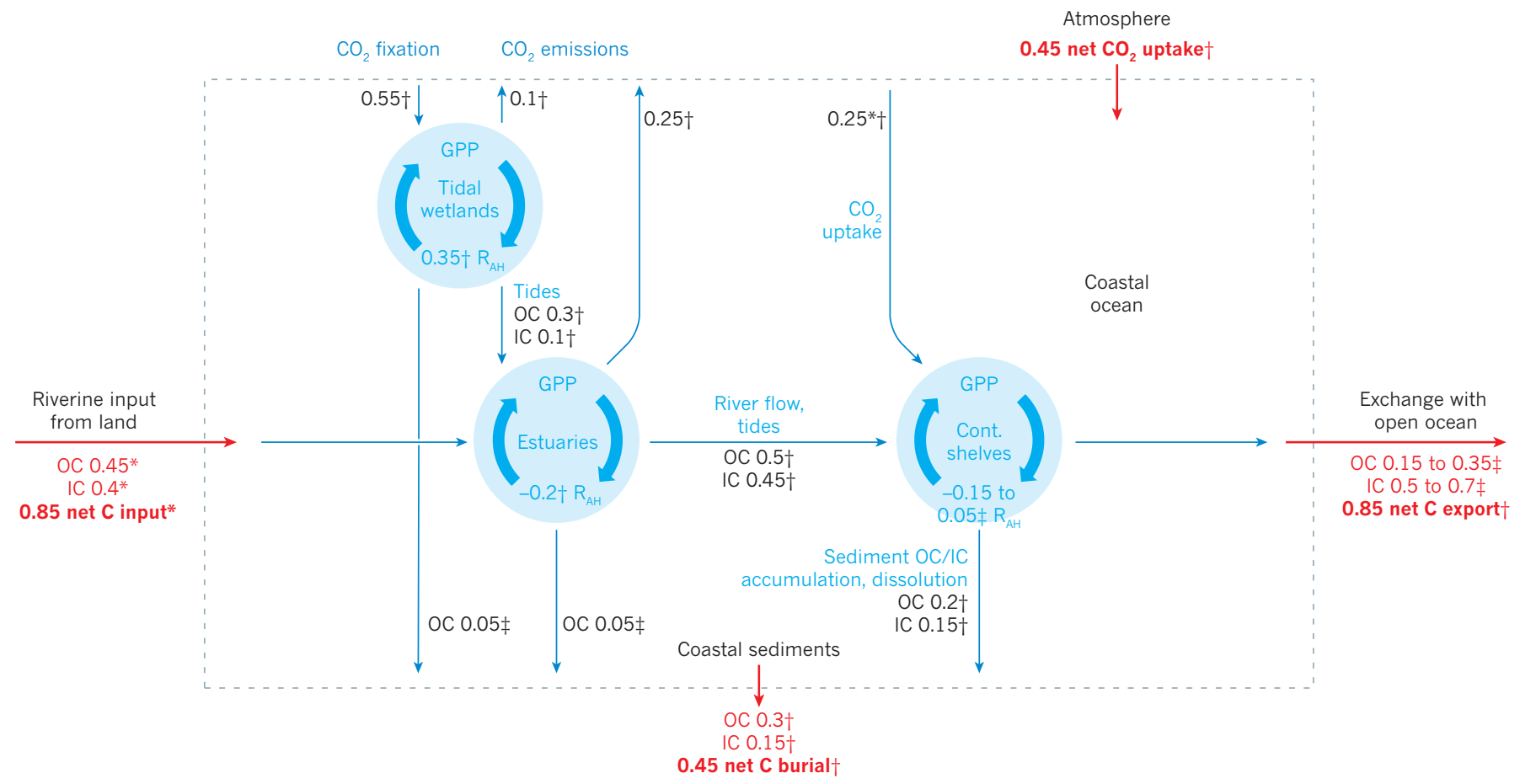

Figure 2 | Organic and inorganic carbon fluxes in the estuarine, tidal wetland and continental shelf subsystems of the coastal ocean. Fluxes between adjacent subsystems and other components of the earth system are regulated by a number of processes (the major ones are shown here). Carbon can flux both within (values in black) and across (values in red) the boundaries of the coastal ocean. All organic carbon (OC) and inorganic carbon (IC) fluxes are presented as positive values, arrows indicate direction of flux. Particulate and dissolved OC fluxes are presented as total OC values. The balance between gross primary production (GPP) and total system respiration (both autotrophic, $\mathrm{A}$, and heterotrophic, $\mathrm{H} ; \mathrm{R}_{\mathrm{AH}}$ ) is net ecosystem production (NEP), with negative values indicating conversion of OC to IC. The IC burial flux takes into consideration calcification. The methods used to estimate flux values and their associated uncertainties are described in Box 1. Typical uncertainties for carbon fluxes: ${ }^{*} 95 \%$ certainty that the estimate is within $50 \%$ of the reported value; $\uparrow 95 \%$ certainty that the estimate is within $100 \%$ of the reported value; $\neq$ uncertainty greater than $100 \%$. Units are $\operatorname{PgCyr}^{-1}\left(1 \mathrm{Pg}=10^{15} \mathrm{~g}\right)$ rounded to $\pm 0.05 \mathrm{PgC} \mathrm{yr}^{-1}$. Within-river fluxes and transformation of carbon are excluded from this analysis. 


\section{BOX 1}

\section{Coastal carbon flux estimates and their uncertainties}

Carbon fluxes and their associated uncertainty estimates presented in this Review are not based on statistical treatment of multiple observed data, as data coverage is poor and often skewed. Rather, most fluxes are based on ranges presented in the literature and the quality of the individual values. Because of the large degree of heterogeneity in the main coastal subsystems and concomitant lack of data, most carbon fluxes in these subsystems have relatively high uncertainties. Riverine carbon fluxes have been estimated over the past three decades and are known with the highest degree of confidence (95\% certainty that the estimate is within $50 \%$ of the reported value $\mathrm{e}^{2,3,9-14}$ ) (Fig. 2). Wetland net primary production rate, carbon burial, $\mathrm{CO}_{2}$ degassing and dissolved inorganic carbon (DIC) export rates are based on values in the literature ${ }^{2,49,86}$. The estuarine $\mathrm{CO}_{2}$ degassing flux is based on the best known syntheses of field data ${ }^{2,33,40,66}$ with moderate confidence $(95 \%$ certainty that the estimate is within $100 \%$ of the reported value) (Figs 2, 3). Organic carbon burial of $0.03-0.2 \mathrm{PgC}^{-1} \mathrm{r}^{-1}$ in wetland and estuarine sediments is the most poorly constrained flux ( $95 \%$ certainty that the estimate is greater than $100 \%$ of the reported value), and we adopt a conservative value $\mathrm{e}^{2,3}$ (Fig. 2). Lateral carbon fluxes from estuaries to continental shelves are estimated from the estuarine mass balance of river and wetland inputs, estuarine $\mathrm{CO}_{2}$ degassing, and marsh and estuarine net ecosystem productivities (NEP), and therefore have moderate confidence.

Owing to recent marked improvements in the quantity and quality of data, present-day continental shelf $\mathrm{CO}_{2}$ gas exchange $\left(0.25 \mathrm{PgCyr}^{-1}\right)$ is among the best estimated of all coastal carbon fluxes (within 50\% uncertainty) $)^{2,39,40,61,66}$. However, because of less-constrained fluxes in enclosed seas and low latitude open shelves (up to $75 \%$ uncertainty) $)^{22}$ (Fig. 3c), we assign an overall uncertainty for shelves of 50-75\%. On the basis of the $\mathrm{CO}_{2}$ uptake flux, the known global shelf surface area $\left(26 \times 10^{6} \mathrm{~km}^{2}\right)$, average gas transport parameter $\left(9.3 \mathrm{~cm} \mathrm{~h}^{-1}\right)$, and present-day atmospheric $p_{\mathrm{CO}_{2}}$ (Fig. $4 \mathrm{~b}$ ), an average surface water $p_{\mathrm{CO}_{2}}$ of $350 \pm 18$ p.p.m. is estimated for the post-industrial shelf. Presentday carbon burial in shelf sediments is also estimated with moderate confidence ${ }^{2,3,50,89}$.

For the pre-industrial shelf (Fig. 4a) a net $\mathrm{CO}_{2}$ degassing flux of around $0.15 \mathrm{PgCyr}^{-1}$ was estimated as the mean of the upper ${ }^{2,50}$ and lower ${ }^{3}$ bounds of reported values. To be compatible with this $\mathrm{CO}_{2}$ degassing flux and a pre-industrial atmospheric $p_{\mathrm{CO}_{2}}$ of 280 p.p.m., an average surface water $p_{\mathrm{CO}_{2}}$ of $298 \pm 18$ p.p.m. is estimated (Fig. 4a). For pre-industrial time, we estimate a shelf NEP of $-0.15 \mathrm{PgCyr}^{-1}$ as the mean between an upper limit, assuming that $60 \%$ of terrestrial organic carbon is respired on shelves and a low bound of zero from ref. 68. However, for present-day shelf NEP, we assumed two scenarios (see 'Pre- and post-industrial shelf carbon budget'). For the pre-industrial and present-day comparison of shelf $\mathrm{CO}_{2}$ fluxes, we held constant river input, estuarine $\mathrm{CO}_{2}$ exchange flux with the atmosphere, NEP and sediment burial constant and then calculated the various organic carbon and inorganic carbon export fluxes by mass balance. Our level of confidence for these estimates is low (Fig. 4a, b). situ, by $0.2 \mathrm{PgCyr}^{-1}$ (ref. 33). The outgassing of estuarine $\mathrm{CO}_{2}$, derived from organic carbon respiration and DIC inputs from rivers and wetlands, releases around $0.25 \mathrm{PgC} \mathrm{yr}^{-1}$ of $\mathrm{CO}_{2}$ into the atmosphere (Figs 2, 3a, b). Although highly uncertain, carbon burial in wetlands and estuaries is probably around $0.1 \mathrm{PgCyr}^{-1}$ (refs 3, 48, 49) (Fig. 2 and Box 1). Our mass balance analysis suggests that estuaries export about $10 \%$ more carbon to continental shelves than they import from rivers (Fig. 2).

Tremendous geomorphological differences between estuaries and a lack of synthetic modelling lead to considerable variability and uncertainty in estimates of estuarine carbon dynamics and export to continental shelves. Estuaries are typically net sources of $\mathrm{CO}_{2}$ to the atmosphere and augment the organic and inorganic carbon supply to shelves (Fig. 2). Climate and land-use changes (specifically sea-level rise and declining river sediment export) are likely to decrease net carbon burial in estuaries and wetlands ${ }^{49}$; however, with anticipated increased inputs from rivers, estuarine export of carbon to continental shelves is likely to increase.

\section{Carbon on continental shelves}

Continental shelves are dynamic interfaces where terrestrial, estuarine and marine organic carbon is recycled (Fig. 1c). Continental shelves occupy only $7-10 \%$ of global ocean area $^{22,50}$ (Fig. 3a). However, shelves contribute $10-30 \%$ of global marine primary production, $30-50 \%$ of inorganic carbon and around $80 \%$ of organic carbon burial in sediments ${ }^{50}$, and could contribute up to about $50 \%$ of the organic carbon supplied to the deep open ocean ${ }^{51}$. Thus, continental shelves are disproportionately important to ocean carbon cycles and budgets.

\section{Shelf organic carbon sources and sinks}

Continental shelf primary production is often related to shelf width and the magnitude of river discharge ${ }^{52}$ (Fig. 1c). On broad river-dominated shelves (for example, Mississippi and Yangtze), primary production on the inner shelf may be limited by high particulate loads, and inputs of riverand estuary-derived organic carbon may dominate the water column and sediments. On broad shelves with lower river discharge (for example,
South Atlantic Bight), sunlight may reach the sea floor and support a significant benthic contribution to shelf primary production and organic carbon $^{51}$. On narrow shelves, pelagic and/or benthic primary production is supported by oceanic inputs of nutrients and is recycled on the shelf $f^{52}$.

Organic carbon burial rates on continental shelves are controlled by multiple mechanisms (Fig. 1c). When river- and estuarine-derived organic carbon enters the coastal zone, about $90 \%$ of it is associated with mineral matrices in organo-clay aggregates ${ }^{24}$. In many highly productive upwelling regions along shelves, organic carbon particles may aggregate by glue-like exopolymers from phytoplankton ${ }^{53}$. In addition to burial, organic carbon in shelf environments is transported to the open ocean through physical resuspension, bioturbation, and mobile and fluid muds along the sea floor ${ }^{54}$ (Fig. 1c). Flocculation processes similar to those in estuaries (Fig. 1b) can also be important in transporting selected forms of DOC and POC from shelf waters to sediments and altering their chemical composition $^{51}$.

\section{Organic carbon reactivity on shelves}

Although terrestrial DOC supplied by rivers can theoretically account for the 4,000-6,000 year residence time of DOC in the global ocean ${ }^{55}$, little terrestrial material is actually detected in the oceans. How this large flux of terrestrial DOC is processed in the coastal ocean is a major remaining question in coastal carbon research. Recent findings show that much (90\% or more) of the reactive aromatic fraction of terrestrial DOC is altered in inner shelf waters by sunlight-driven photoreactions to produce highly stable, ubiquitous and presumably long-lived components of oceanic DOC ${ }^{56,57}$. Bacterial alteration of terrestrial plant-derived lignin can account for additional DOC losses (up to 30\% of the photochemical losses) in river-dominated shelf waters ${ }^{58}$. There is, thus, a growing consensus that much of the terrestrial DOC becomes chemically altered, rather than completely oxidized to $\mathrm{CO}_{2}$, on shelves. This may help to reconcile the disagreement between riverine inputs and ocean DOC residence times. In contrast to terrestrial organic carbon, $50-90 \%$ of the organic carbon that is derived from marine primary production is rapidly recycled 
on continental shelves. Reactive marine material may also enhance the metabolism of less reactive terrestrial organic carbon in shelf waters and sediments ${ }^{59}$.

\section{Carbon-dioxide exchange in shelf waters}

Tsunogai et al. ${ }^{60}$ first pointed out, in 1999, the importance of continental shelf $\mathrm{CO}_{2}$ uptake to the carbon cycling and climate change

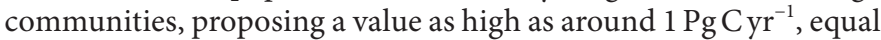
to $50 \%$ of the open ocean $\mathrm{CO}_{2}$ uptake known at the time. Most recent syntheses are based on up-scaling methods whereby different shelf systems are classified by dividing them into a few provinces ${ }^{61}$ or typologies $^{40}$. These estimates suggest a lower, but, relative to the global ocean and land ${ }^{41}$, still significant net atmospheric $\mathrm{CO}_{2}$ uptake flux of 0.25 $\mathrm{PgCyr}^{-1}$ (Fig. 3a).

Inner continental shelf waters close to land tend to be sources of $\mathrm{CO}_{2}$, mostly due to their high rates of respiration of terrestrial and estuarine organic carbon and lateral transport of high $\mathrm{CO}_{2}$ waters from adjacent inshore systems. By contrast, mid- to outer-shelf waters are a sink of $\mathrm{CO}_{2}$ (ref. 62). This general pattern results from decreased terrestrial organic carbon supply, increased primary production as light conditions improve offshore, and increased accessibility to nutrients supplied by upwelling and mixing across the shelf break ${ }^{63}$. This pattern and the inshore to offshore shift from $\mathrm{CO}_{2}$ release to $\mathrm{CO}_{2}$ uptake across shelves can be altered greatly in larger river plumes ${ }^{64}$ or in upwelling dominated shelves ${ }^{65}$ (Fig. 1c) and depends to a significant extent on physical conditions such as wind stress and river discharge. Furthermore, a striking latitudinal contrast in shelf-water-atmosphere $\mathrm{CO}_{2}$ fluxes emerges from a global synthesis of shelf systems. Present-day shelves located between $30^{\circ}$ and $90^{\circ}$ latitude are, in general, sinks for atmospheric $\mathrm{CO}_{2}$ whereas shelves located between the equator and $30^{\circ}$ tend to be sources of $\mathrm{CO}_{2}$ (or nearly neutral) to the atmosphere ${ }^{61,66}$ (Fig. 3c). This latitudinal pattern could, in part, be explained by the fact that around $60 \%$ of river organic carbon is exported to lower latitude shelves and respired under the higher mean temperatures in these systems $\mathrm{s}^{2,10}$. Of increasing importance is that the western Arctic Ocean margin, in particular the nutrient-rich Chukchi Sea, has become a rapidly increasing global shelf sink for atmospheric $\mathrm{CO}_{2}$ over the past decade ${ }^{67}$ due to greater annual retreat of sea ice - a major barrier to gas exchange - as a result of climate warming.

\section{Autotrophic-heterotrophic balance}

Before the extensive alteration of terrestrial landscapes and industrial fertilizer production, estuarine and continental shelf waters were on the whole thought to be net heterotrophic (they released more $\mathrm{CO}_{2}$ to the atmosphere than was fixed by primary production, as a result of their respiration of terrestrial and tidal wetland organic carbon inputs ${ }^{68,69}$ ). Indeed, almost every river and estuary globally, for which data are available, is today a strong source of $\mathrm{CO}_{2}$ (refs $1,40,66$ ). These systems were probably an equally strong - if not stronger - source of $\mathrm{CO}_{2}$ in the past when atmospheric $p_{\mathrm{CO}_{2}}$ was lower.

There is currently no consensus as to whether present-day continental shelves are net autotrophic or heterotrophic, owing, in part, to a lack of concurrent respiration measurements to go along with the abundant primary productivity measurements that have been made in shelf waters ${ }^{70}$. The complexity of coastal systems further hampers proper upscaling for modelling (Box 2). A school of thought suggests that continental shelves as a whole are now net autotrophic because of increased anthropogenic nutrient supply ${ }^{50,63,69}$, which in some systems exceeds deep ocean nutrient inputs by upwelling or mixing across the shelf break ${ }^{63}$. This view is consistent with the observation that most shelves are a net sink for atmospheric $\mathrm{CO}_{2}$ (refs $40,61,66$ ). Thus, it has been postulated that the coastal ocean as a whole has shifted from a net heterotrophic to an increasingly net autotrophic state, which has in turn favoured a reversal from shelves being a $\mathrm{CO}_{2}$ source to a $\mathrm{CO}_{2}$ sink in recent decades ${ }^{69}$. This hypothesis is substantiated by results from coarse-grained box models (Box 2). Although it is important to establish whether such a shift has occurred, if it has, its exact magnitude and timing remain highly uncertain.

Similar to estuaries, continental shelves are highly heterogeneous coastal subsystems. Carbon dynamics in some shelves are controlled entirely by ocean circulation, whereas in others they are controlled largely by riverine inputs. Uncertainties in shelf carbon fluxes are significant (Fig. 2) but cannot yet be adequately constrained

\section{BOX 2}

\section{Modelling the coastal carbon cycle}

Earth system models (ESMs) are climate models that can include physical processes, as well as biogeochemical cycles, and which allow a representation of anthropogenic processes ${ }^{95}$. They describe processes within and between the atmosphere, ocean, cryosphere, and terrestrial and marine biosphere. ESMs include coarse-grained box models, models of intermediate complexity and comprehensive tridimensional global climate models that incorporate biogeochemical processes, such as carbon cycle and atmospheric chemistry. However, with the exception of a few box models, ESMs are at present limited by their lack of coupling between atmosphere, land and ocean components through lateral flows of carbon (and nutrients; Box 3) along the land-ocean continuum ${ }^{3}$. The delivery of riverine carbon is included as a forcing condition in large-scale ocean component models ${ }^{96}$, but spatially resolved ESMs do not simulate the riverine carbon fluxes dynamically.

Attempts to estimate the historical evolution of the aquatic fluxes from land to ocean and their effects on estuarine and continental shelf carbon dynamics have so far relied solely on globally averaged box models ${ }^{69}$. Although these models are extremely valuable for testing further conceptual ideas, they rely on highly parameterized process formulations. In addition, global box models do not account for the wide diversity of estuarine and shelf systems, nor do they mechanistically represent the effect of land-use changes on terrestrial biogeochemistry and riverine fluxes.

State-of-the-art ESMs contain routing schemes for riverine water flows at a spatial resolution of $0.5^{\circ}$. At this resolution, about 500 rivers that contribute around $80 \%$ of the total organic carbon delivery to the oceans may now be resolved. Furthermore, with the development of eddy-permitting runs at a resolution of about $0.25^{\circ}$, shelf carbon dynamics are increasingly better captured. Including these dynamics will allow better resolution of important processes such as the air-sea $\mathrm{CO}_{2}$ exchange that results from large-scale coastal eddies or the physical transport divergence of carbon across coastal boundaries and the shelf break. The largest rivers of the world produce coastal plumes which can also be reasonably well captured ${ }^{97}$, whereas narrow coastal systems such as eastern boundary currents will still require higher resolution ${ }^{98}$. For estuaries and tidal wetlands a resolution of $0.25-0.5^{\circ}$ is too coarse, and specific modelling approaches that rest on mechanistically rooted upscaling strategies need to be designed to better constrain their roles in ocean and global carbon cycles and assess their sensitivity to anthropogenic disturbances. Improved mechanistic descriptions of ecosystem and biogeochemical processes are also needed as the current formulations may not be able to sufficiently capture the complexity of coastal ocean dynamics and their response to enhanced terrestrial inputs ${ }^{3}$. 


\section{The role of elemental stoichiometry}

Coastal subsystems tend to release $\mathrm{CO}_{2}$ to the atmosphere simply because of the contrasting elemental stoichiometry (the ratio of carbon to nitrogen, C:N) of terrestrial organic matter (TOM) decomposition and aquatic primary production. TOM carried to the coast by rivers typically has a high C:N (30:1 to 60:1) (Box Fig., left), whereas organic matter produced by algae such as phytoplankton in coastal systems has C:N near 7:1 (Box Fig., right).

The stoichiometry of decomposition and production crucially influences the metabolic balance of aquatic systems (the ratio of gross primary production (GPP) to ecosystem respiration (R)). During TOM decomposition, 30-60 moles of inorganic carbon (that is, $\mathrm{CO}_{2}$ ) are produced for every 1 mole of inorganic nitrogen produced. If $100 \%$ of the remineralized nitrogen is recycled and taken up by algal primary production, only 7 moles of inorganic carbon can be taken up by new algal biomass having a $\mathrm{C}: \mathrm{N}$ stoichiometry of $7: 1$. That is, relative to nitrogen, much more $\mathrm{CO}_{2}$ is produced during decomposition than is taken up during primary production. Thus, coastal systems with significant decomposition of high C:N TOM will tend to be heterotrophic, with respiration (production of $\mathrm{CO}_{2}$ ) exceeding primary production (consumption of $\mathrm{CO}_{2}$ ). Equally important in controlling the net uptake or release of $\mathrm{CO}_{2}$ are the rates of TOM decomposition (days to years) compared with algal

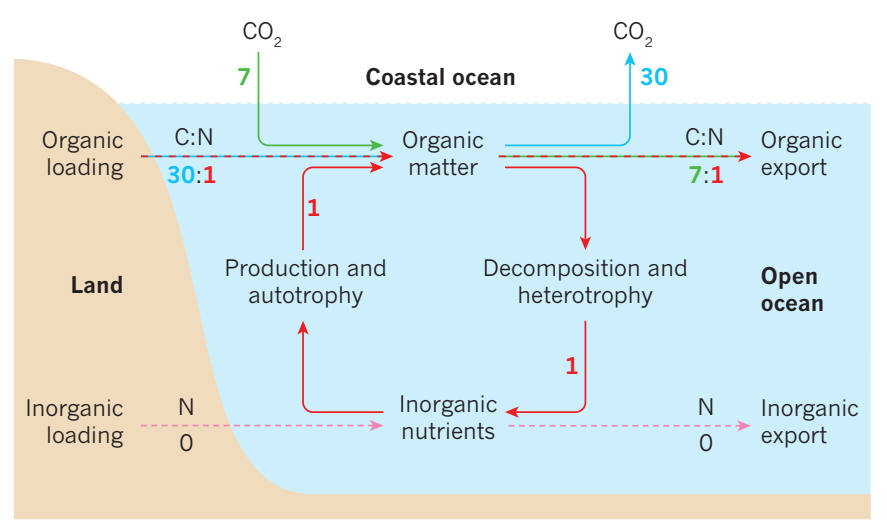

organic matter decomposition (hours to months) and algal primary production (hours to days) relative to water residence time $e^{99,100}$. This mismatch in time scales of autotrophic and heterotrophic processes can drive the net metabolic balance ${ }^{35}$. The system shown in the figure is net heterotrophic $(P<R)$ and NEP is $-23(P-R)$. Nitrogen loaded from land and recycled is shown in red, terrestrial carbon is blue and recycled production is green. through statistical treatments of available data sets (Box 1). These uncertainties represent an important barrier for the integration of coastal systems in global carbon-cycle assessments. Although the magnitude of each flux may be revised in further assessments such that uncertainties are reduced, this is unlikely to affect our analysis that shelf-atmosphere $\mathrm{CO}_{2}$ exchanges and lateral carbon fluxes on shelves are important to the global carbon balance. Changes in riverine and estuarine organic carbon and nutrient supply and increasing atmospheric levels of $\mathrm{CO}_{2}$ are all postulated to alter shelf-atmosphere-open-ocean exchanges.

\section{Human impacts on the coastal carbon cycle}

Major uncertainties remain in our understanding of the natural, undisturbed carbon cycle of the coastal ocean. Activities such as land-use modification, waterway impoundment, nutrient inputs, wetland degradation and climate change add even greater complexity and uncertainty, making it difficult to differentiate the natural and anthropogenic drivers affecting changes in the coastal carbon cycle. Although a number of drivers of anthropogenic disturbance to river and estuarine carbon fluxes have been identified, quantitative estimates of their effect on these fluxes are very poorly constrained. Understanding the exact direction and magnitude of different human impacts on individual fluxes is not only important in both coastal and global carbon budgets but also for determining the global terrestrial $\mathrm{CO}_{2}$ sink - a flux defined as the residual from all other components of the anthropogenic $\mathrm{CO}_{2}$ budget ${ }^{3,71}$. Research on riverine organic carbon export, in particular, shows that at least part of the anthropogenic $\mathrm{CO}_{2}$ taken up by land ecosystems is exported to the coastal ocean ${ }^{3,4}$. The change in land carbon storage as synthesized by the IPCC ${ }^{4}$ and others may thus be overestimated because a significant fraction of the displaced carbon is stored in coastal waters and sediments ${ }^{3}$. Quantification of the temporal evolution of coastal carbon transfers and fluxes, and the incorporation of coastal carbon processes in Earth system models is also necessary to support relevant policies and mitigation strategies (Box 2).

\section{Human perturbations to rivers and estuaries}

Land management is now considered to be a primary driver for changing riverine carbon exports to the coastal ocean (Fig. 1a). Agricultural practices have led to an increase in the movement of sediment and POC from land ${ }^{72}$. This does not necessarily lead to increased carbon fluxes to the coastal ocean, however, because much of the terrestrial material is redeposited on land ${ }^{73}$ or trapped in man-made reservoirs and agricultural impoundments ${ }^{11}$. For example, reservoirs are thought to have reduced current POC fluxes to around $90 \%$ of the pre-anthropogenic level ${ }^{11}$. Similarly, agriculturally enhanced riverine fluxes of bicarbonate and other major ions are now reported in numerous regions and have increased by as much as $40 \%$ in systems such as the Mississippi, owing to liming and hydrological alterations ${ }^{74}$. In addition, organic carbon exported by agricultural landscapes may have different chemical characteristics, and lower overall susceptibility to photochemical and microbial degradation than organic carbon from less altered or forested landscapes ${ }^{75}$. Conversion of wetland and peatland systems to other land uses can also affect the amounts and ages of organic carbon transported to rivers and estuaries $^{76,77}$. Newer spatially resolved models that include riverine fluxes at the scale of large watersheds suggest increased fluxes, owing to $\mathrm{CO}_{2}$ stimulation of terrestrial primary production under future climate scenarios ${ }^{15}$.

There is growing evidence that humans have altered the riverine flux of carbon to the coastal ocean on regional to global scales. Regional increases in riverine DOC concentration have been reported, with multiple mechanisms suggested ${ }^{78}$. It is also increasingly likely that global DIC fluxes have increased as a result of liming and anthropogenic acid additions to watersheds $^{74,79}$, and that POC fluxes have decreased owing to changing precipitation regimes and land and river management. Although future climate change is predicted to lead to an increase in river carbon fluxes (Fig. 1a), it is also likely to lead to increased uncertainties in predicting these fluxes.

Human activities associated with estuaries, such as land-use change, bulkhead construction, wastewater discharge, wetland removal and dredging, are increasingly important factors that affect estuarine carbon sources, cycling and budgets ${ }^{3}$ (Fig. 1b). Elevated levels of organic carbon respiration in productive, nutrient-rich estuarine waters and river plumes have recently been found to amplify the effects of ocean acidification on estuarine ecosystems $\mathrm{s}^{80,81}$. In addition, the microbial oxidation of ammonia and organic carbon from urban wastewater discharge generates acids, leading to very low $\mathrm{pH}$ and high $\mathrm{p}_{\mathrm{CO}_{2}}$ conditions and enhancing 
$\mathrm{CO}_{2}$ degassing in some estuarine waters ${ }^{31,82}$. Changes in physical drivers such as river discharge, sea-level rise or storm frequency and intensity may fundamentally alter estuarine biogeochemical processes (Box 3 ) and consequently $\mathrm{CO}_{2}$ and DIC exchanges between estuaries, the atmosphere and continental shelves ${ }^{3,83}$ (Fig. 1b). Continued environmental changes in estuaries and associated wetlands will have potential impacts on the direction and magnitude of estuarine internal organic and inorganic sources and sinks, and the magnitude of both their atmospheric $\mathrm{CO}_{2}$ emissions and their export of organic and inorganic carbon to shelves.

\section{Human impacts on shelf organic carbon}

Human impacts on processes such as river discharge, nutrient inputs and climate warming have also resulted in changes to continental shelf organic and inorganic carbon cycling. Terrestrially derived DOC from soils and thawing high-latitude peatlands may limit light penetration and primary production in continental shelf waters (Fig. 1c), and its degradation by sunlight can result in production of radiatively important trace gases such as $\mathrm{CO}_{2}, \mathrm{CO}$ and $\mathrm{CH}_{4}$. These concerns are compounded in the environmentally sensitive Arctic Ocean, where recent marked decreases in summer time sea-ice cover are hypothesized to lead to an increasing role for photochemistry in Arctic shelf organic carbon cycling ${ }^{84}$. In addition, recent reductions in POC loads by river damming globally (Fig. 1a) have resulted in relatively greater contributions of estuarine-derived organic carbon $^{59}$, which is generally considered to be more biologically reactive than terrestrial organic carbon. Increased terrestrial export of nutrients and carbon by rivers due to agricultural activities and land-use change has also led to excess primary production and organic carbon accumulation in estuarine and shelf waters and sediments, which in turn may lead to oxygen-depleted hypoxic conditions - now considered to be a major global environmental issue in temperate and tropical coastal systems ${ }^{85}$.

\section{Pre- and post-industrial shelf carbon budget}

The continental shelf was probably net heterotrophic during pre-industrial times, because a large fraction of terrestrial organic carbon export must have been respired in shelf waters ${ }^{2,50,68,69}$. In the following analysis, we assume a pre-industrial shelf net ecosystem production (NEP) of $-0.15 \mathrm{PgCyr}^{-1}$ (a mean between $60 \%$ of terrestrial organic carbon respiration and shelf NEP of zero ${ }^{68}$ ) and a net shelf $\mathrm{CO}_{2}$ degassing flux of about $0.15 \mathrm{PgCyr}^{-1}$ (a mean between a high bound $\mathrm{d}^{50,68}$ and a low bound ${ }^{3}$ ) (Fig. 4a). This $\mathrm{CO}_{2}$ degassing flux, together with the known global shelf area, average gas transport parameter and pre-industrial atmospheric $p_{\mathrm{CO}_{2}}$ (Fig. 4a), requires an average pre-industrial surface water $p_{\mathrm{CO}_{2}}$ of $298 \pm 18$ ppm (Box 1). Our mass balance analysis also estimates moderate DIC and DOC export fluxes to the ocean during pre-industrial times (Fig. 4a). The combined pre-industrial offshore DIC and organic carbon fluxes (0.45 $\mathrm{PgC}_{\mathrm{yr}}{ }^{-1}$ ) estimated here (Fig. $4 \mathrm{a}$ ) are therefore much less than the riverine or estuarine DIC and organic carbon fluxes $\left(0.95 \mathrm{PgC}^{-1}\right)$ (Fig. 2) because of extensive $\mathrm{CO}_{2}$ outgassing and burial.

A drastically different scenario emerges for the post-industrial period, when shelves are at present a $\mathrm{CO}_{2}$ sink and calculated to have an average global shelf $p_{\mathrm{CO}_{2}}$ of $350 \pm 18$ ppm under present-day atmospheric $p_{\mathrm{CO}_{2}}$ of 380 p.p.m. (Fig. $4 \mathrm{~b}$ and Box 1). Two mechanisms may be responsible for the shelf switching from a $\mathrm{CO}_{2}$ source to $\mathrm{a} \mathrm{CO}_{2}$ sink between pre- and post-industrial times. The prevailing view assumes a shift in continental shelf NEP over the industrial age from net heterotrophic to increasingly net autotrophic conditions (NEP up to $+0.05 \mathrm{PgC}^{-1}$ ). This is a result of enhanced biological uptake of atmospheric $\mathrm{CO}_{2}$ owing to stimulation of shelf primary production by increased anthropogenic nutrient inputs from land ${ }^{69}$. This mechanism would contribute to the reversal in shelf $\mathrm{CO}_{2}$ flux over the industrial era (Box 3 ) and implies an increase in organic carbon export from shelves to the open ocean to about $0.35 \mathrm{PgCyr}^{-1}$ (Fig. $4 \mathrm{~b}$ ) or higher ${ }^{86}$ and a moderate increase in DIC export to about $0.5 \mathrm{PgC}^{-1}$.

Here we propose an alternative mechanism that could also explain the present-day continental shelf $\mathrm{CO}_{2}$ sink. This mechanism requires no change in shelf NEP but simply an increased physical uptake of atmospheric $\mathrm{CO}_{2}$, as atmospheric levels of $\mathrm{CO}_{2}$ have risen to a much greater
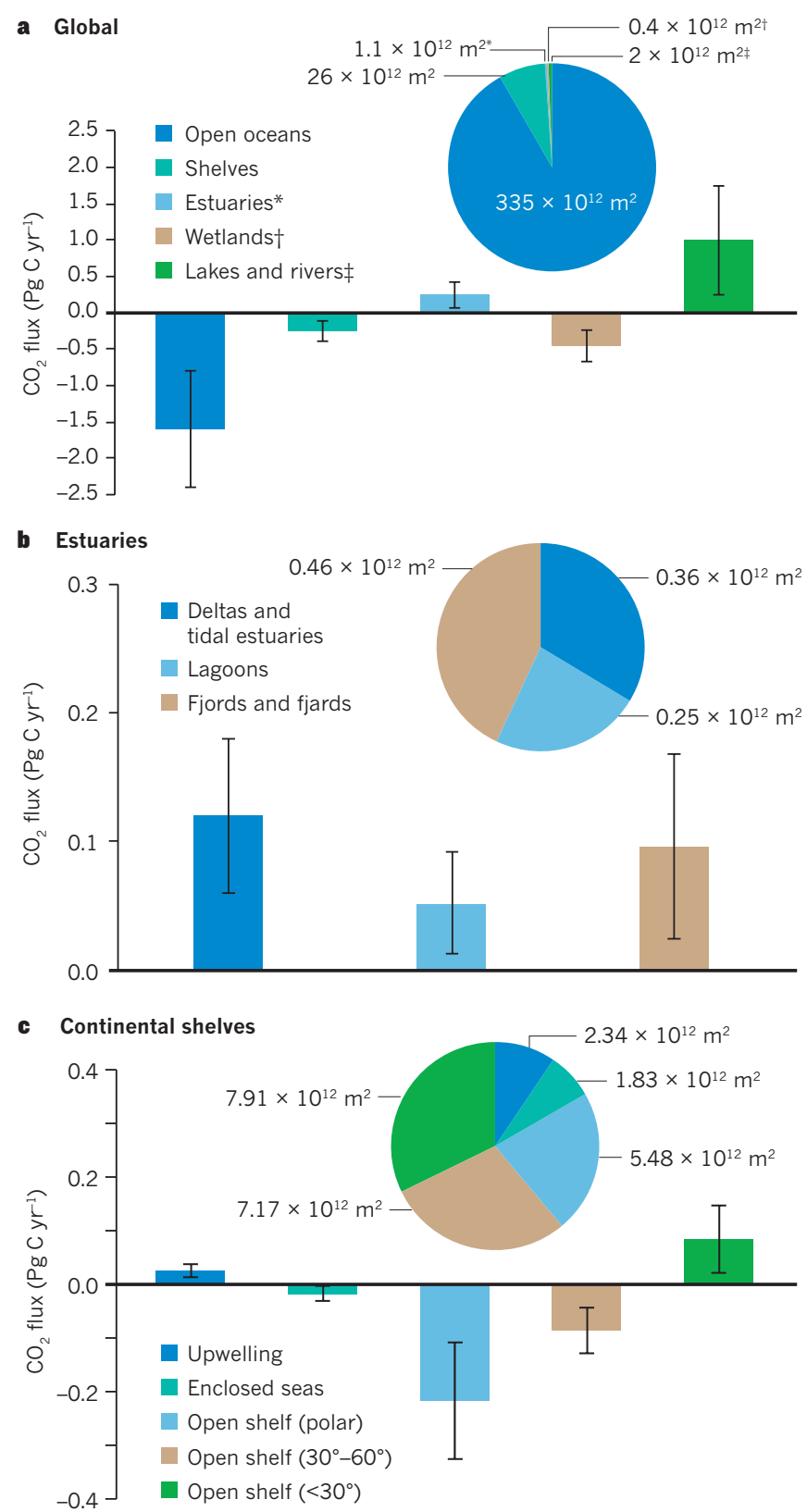

Figure 3 Air-surface water $\mathrm{CO}_{2}$ exchange fluxes of different aquatic systems. a, The global areas of major aquatic systems. b. The $\mathrm{CO}_{2}$ flux and global areas of river deltas and embayments (estuary type I and II in refs 33 and 40), coastal lagoons (type III), and fjords and fjards (type IV) (note that large river plumes extending onto and across continental shelves are not included, although it is known that they are a $\mathrm{CO}_{2}$ sink for the atmosphere). c, Carbon flux and global areas of continental shelves. Continental shelves freely exchange with the open ocean in low latitudes $\left(0-30^{\circ}\right)$, temperate or midlatitudes $\left(30-60^{\circ}\right)$ and polar or high latitudes $\left(60-90^{\circ}\right)$, upwelling systems, and enclosed shelf seas. We assigned an uncertainty of $<50 \%$ to each flux term except inland waters, fjords and fjards, enclosed seas and low latitude open shelves, which have an assigned uncertainty of $50-100 \%$ because of the very sparse data coverage. Flux values and their uncertainties were derived according to the methods in Box 1.

degree than those of shelf waters ${ }^{2}$. In addition to explaining the shelf switching from a $\mathrm{CO}_{2}$ source to a $\mathrm{CO}_{2}$ sink over the industrial age, this alternative mechanism would also allow for only a small or no change in shelf organic carbon export, whereas shelf DIC export would be greatly

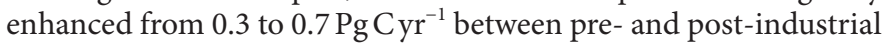
times (Fig. 4a, b). Observations in southeastern US shelf waters ${ }^{87}$ support the predicted strong present-day DIC export across the coastal 


\section{a Pre-industrial continental shelf}

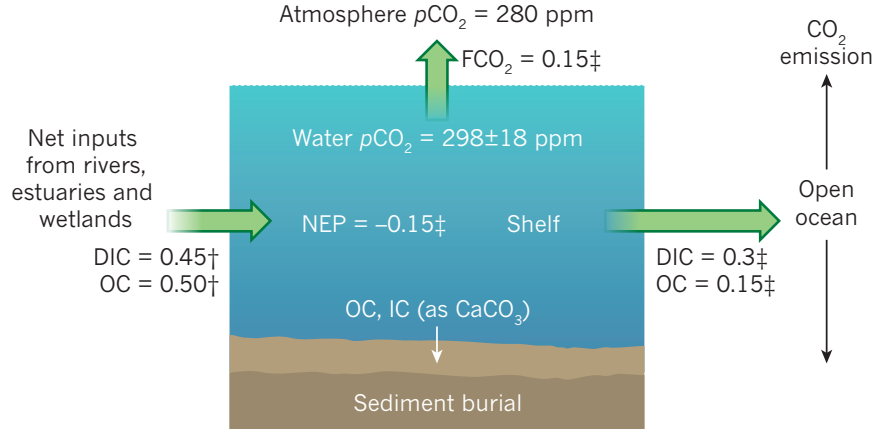

b Present day continental shelf

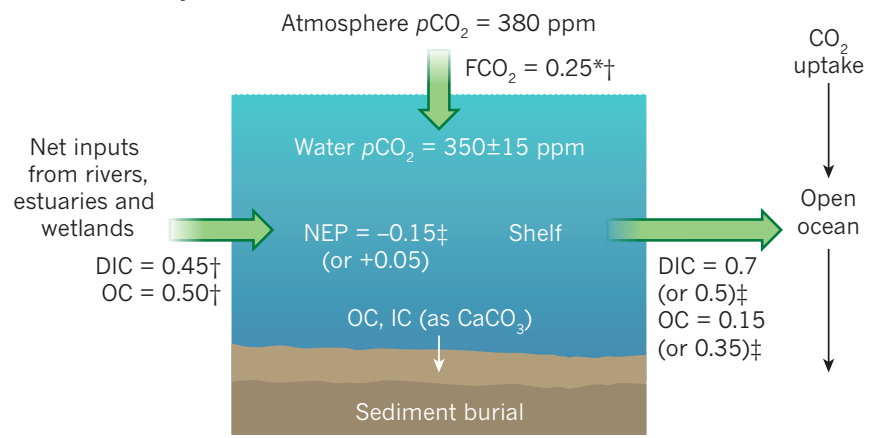

Figure $4 \mid p_{\mathrm{CO}_{2}}$ levels, net ecosystem production and organic and inorganic carbon fluxes in pre-industrial and current continental shelves. According to this model, a, the entire pre-industrial continental shelf was a source of $\mathrm{CO}_{2}$ to the atmosphere, but $\mathbf{b}$, it became $\mathrm{CO}_{2}$ sink at some point in the latter twentieth century owing to increased atmospheric $p_{\mathrm{CO}_{2}}$. We further suggest that together with the current known $\mathrm{CO}_{2}$ uptake from the atmosphere, increased shelf export of dissolved inorganic carbon (DIC) would lead to an increased DIC inventory in the open ocean. Organic carbon, OC; net ecosystem production, $\mathrm{NEP} ; \mathrm{CO}_{2}$ flux, $\mathrm{FCO}_{2}$. All carbon fluxes including NEP have units of $\mathrm{PgC}_{\mathrm{yr}}{ }^{-1}$. Flux estimates were derived as described in Box 1. We assign an uncertainty of $100 \%$ for the pre-industrial air-sea $\mathrm{CO}_{2}$ flux, larger than the current $\mathrm{CO}_{2}$ flux uncertainty of $50-75 \%$. ${ }^{*} 95 \%$ certainty that the estimate is within $50 \%$ of the reported value; $\uparrow 95 \%$ certainty that the estimate is within $100 \%$ of the reported value; ¥uncertainty greater than $100 \%$ (Box 1). The sea surface average $p_{\mathrm{CO}_{2}}$ value and its associated current or pre-industrial uncertainties were back-calculated from the assigned air-sea $\mathrm{CO}_{2}$ flux, known atmospheric $p_{\mathrm{CO}_{2}}$ value, shelf area and average gas-exchange parameter ${ }^{2}$, as described in Box 1.

open ocean boundary. Regardless of the specific mechanism, the present-day combined organic and inorganic carbon flux across the shelf break $\left(0.85 \mathrm{PgC}^{-1}\right)$ is significantly smaller than the combined inputs $\left(1.3 \mathrm{PgC}^{-1}\right)$ from rivers, estuaries or wetlands $\left(0.95 \mathrm{PgC}^{-1}\right)$ and the atmosphere $\left(0.25 \mathrm{PgC}^{-1}\right)$ (Fig. $\left.4 \mathrm{~b}\right)$, making the modern coastal ocean, as a whole, an important zone of global carbon sequestration (0.35 $\mathrm{PgC}^{-1}$ ) (ref. 3).

The differences in the export fluxes of organic and inorganic carbon by these two proposed mechanisms are great, but subject to large uncertainties (Box 1). In addition to the associated uncertainties in the air-sea $\mathrm{CO}_{2}$ flux owing to limited data coverage, we also note that to focus on the potential importance of changing $\mathrm{CO}_{2}$ levels and nutrient enrichment, we have assumed that both organic and inorganic carbon export to shelves and burial in shelf sediments have remained constant (Fig. 4a, b). If instead these export and burial fluxes have increased over the industrial period, then lateral export fluxes could be significantly smaller than those suggested here (see ref. 3 for details).

Development of agricultural soils, deforestation, sewage inputs, enhanced weathering of continental surfaces (Fig. 1a) and loss of coastal wetlands (Fig. 1b) have probably caused changes in both estuarine and continental shelf carbon fluxes over the past century ${ }^{3}$. Increasing ocean acidification will also lead to changes in the magnitudes of atmospheric $\mathrm{CO}_{2}$ exchange and lateral DIC flux by affecting $\mathrm{CO}_{2}$ and calcium carbonate precipitation and dissolution ${ }^{88,89}$. The interactions between multiple coastal ocean stressors, such as acidification and eutrophication and the associated hypoxia, may add another level of complexity to predicting future changes in organic and inorganic carbon and $\mathrm{CO}_{2}$ fluxes in coastal oceans ${ }^{2,80}$.

\section{Charting the course ahead}

Our qualitative and quantitative understanding of organic and inorganic carbon fluxes in the coastal ocean is important for achieving closure on the oceanic and global carbon budgets. Several significant conclusions and questions arise from our analysis of the coastal carbon cycle and the effects of human perturbations that can help to guide future research. For example, only recently has it become clear that the direction and magnitude of estuarine and continental shelf $\mathrm{CO}_{2}$ exchange with the atmosphere is highly dependent on the terrestrial organic carbon budget and nutrient supplies to the coastal ocean ${ }^{2,33}$ (Figs 1, 2 and Box 3). In consequence, the integration of coastal and global carbon cycles is still in its early stages, and additional efforts are required to fully merge component subsystems such as tidal marshes and mangroves with these budgets ${ }^{7,49}$ (Figs 1b, 3b). Direct measures of wetland carbon exchanges with the atmosphere and export to estuaries, for example using atmospheric eddy covariance techniques, coupled with high temporal resolution export monitoring, will greatly improve this integration. This is particularly important in view of the potential effects of accelerating sea-level rise and global warming on the carbon supply of these ecosystems to the coastal ocean.

We also currently lack the necessary measurements and data to fully categorize the high degree of heterogeneity of coastal systems that would allow extrapolation of our understanding of carbon dynamics at local scales to the global scale. The very large uncertainty associated with estimates of air-water $\mathrm{CO}_{2}$ fluxes in coastal waters and wetlands (about $50 \%$ or $\pm 0.2 \mathrm{PgCyr}^{-1}$; Fig. 2) further impedes satisfactory assessment of the overall $\mathrm{CO}_{2}$ exchange from land and ocean to the atmosphere. The uncertainty in present-day air-surface $\mathrm{CO}_{2}$ flux estimates in coastal systems must also be reduced before meaningful predictions of the effects of climate change on future fluxes can be made. To resolve these issues, long-term observations and field studies targeted at systems that capture the range of heterogeneity of coastal systems are needed. New technologies, including recent advances in characterizing the sources, ages and reactivity of less stable modern organic carbon (for example, from phytoplankton and modern vascular plants $)^{90-93}$ and new $\mathrm{CO}_{2}, \mathrm{pH}$ and DOC sensors should help to resolve the fate of organic and inorganic carbon in future coastal carbon budgets. Sensitivity analyses of coupled hydrodynamic-biogeochemical model parameters will highlight where additional research focus is needed to further reduce uncertainty in model predictions. These next steps will improve our prediction of coastal carbon dynamics for the full range of estuarine, wetland, and continental shelf subsystems and our understanding of these subsystems' sensitivity to human activities at the larger scales of Earth system models ${ }^{3}$ (Box 2).

There is growing consensus among Earth system scientists that there are unequivocal anthropogenic signals that can be measured in many of the carbon pools and fluxes in all the major Earth subsystems. Although rivers and their associated watersheds have some of the longest-running evidence of human impacts ${ }^{74}$, we are now recognizing the propagation of these impacts to estuaries and their associated wetlands, as well as to continental shelves. Thus, there is a crucial need for design and implementation of field and modelling activities for carbon-cycle research on coupled terrestrial-ocean systems that bridge, or even eliminate, conventionally defined subsystem boundaries. Nitrogen enrichment of continental shelves from watersheds represents one example of impact propagation across boundaries. Studies designed to examine the mechanisms and time frames of this propagation are needed to assess how future human activities and climate changes will amplify or dampen both the spatial extent of the propagation and its impact.

If the shelf has indeed shifted from an overall pre-industrial $\mathrm{CO}_{2}$ source 
to a present-day and future $\mathrm{CO}_{2}$ sink, does this also indicate a shift in shelf ecosystem metabolism from a net heterotrophic to a net autotrophic state over the past few decades ${ }^{69}$ ? This possibility is supported by the massive global increase in nutrient inputs from most rivers to the coastal ocean owing to agricultural fertilizers and other human-related sources on land. Enhanced nutrient inputs have undoubtedly shifted local trophic states both spatially and temporally, and may have even reversed some shelf ecosystems from net heterotrophy to net autotrophy. However, we suggest that coastal systems globally (excluding tidal wetlands) are overall heterotrophic, respiring more organic carbon than they synthesize. The much greater amounts of organic carbon (supporting heterotrophy) relative to inorganic nitrogen (supporting autotrophy) in river waters that discharge into coastal systems (Box 3) support this contention. In addition, losses of inorganic nitrogen ( $80 \%$ or more) by denitrification in coastal systems ${ }^{94}$ further limit autotrophy.

To reconcile the present simultaneous net heterotrophic state and uptake of $\mathrm{CO}_{2}$, we suggest that continental shelves might still be a $\mathrm{CO}_{2}$ source to the atmosphere if current atmospheric $\mathrm{p}_{\mathrm{CO}_{2}}$ was lower (for example, below 350 p.p.m., the likely present-day average coastal water $p_{\mathrm{CO}_{2}}$; Fig. $4 \mathrm{~b}$ ). The reason $p_{\mathrm{CO}_{2}}$ is not higher in today's shelf waters may result from the short residence times (generally less than a few months, and shorter than the air-sea $\mathrm{CO}_{2}$ equilibration time scale) of their water masses, preventing full accumulation of anthropogenic $\mathrm{CO}_{2}$ in these waters ${ }^{2}$ (Fig. $4 \mathrm{a}, \mathrm{b}$ ). If $p_{\mathrm{CO}_{2}}$ levels continue to increase faster in the atmosphere than in shelf waters, then the coastal ocean will take up more $\mathrm{CO}_{2}$ from the atmosphere and export more DIC to the open ocean. This postulation should be examined through long-term time series measurements of carbon fluxes (for example, moored arrays at fixed shelf stations) such as those that are common in open ocean and terrestrial monitoring, and decadal across-shelf transects in representative coastal systems. If coastal ocean $\mathrm{CO}_{2}$ uptake and lateral DIC export become increasingly important relative to a stabilizing or decreasing open ocean $\mathrm{CO}_{2} \operatorname{sink} \mathrm{k}^{71}$, this mechanism must be incorporated in future models of ocean-atmosphere $\mathrm{CO}_{2}$ exchange and ocean acidification.

\section{Received 29 June; accepted 28 October 2013.}

1. Cole, J. J. et al. Plumbing the global carbon cycle: integrating inland waters into the terrestrial carbon budget. Ecosystems 10, 172-185 (2007).

This paper presents a new model of the quantitatively significant roles of inland waters, including streams and rivers and estuaries, in transporting and burying terrestrial carbon, degrading reactive organic carbon, and $\mathrm{CO}_{2}$ emissions.

2. Cai, W.-J. Estuarine and coastal ocean carbon paradox: $\mathrm{CO}_{2}$ sinks or sites of terrestrial carbon incineration? Annu. Rev. Mar. Sci. 3, 123-145 (2011).

3. Regnier, P. et al. Anthropogenic perturbation of the carbon fluxes from land to ocean. Nature Geosci. 6, 597-607 (2013)

4. IPCC. Climate Change 2013. The Physical Science Basis. Contribution of Working Group I to the Fifth Assessment Report of the Intergovernmental Panel on Climate Change (eds Stocker, T. F. et al.) (Cambridge Univ. Press, in the press)

5. Aufdenkampe, A. K. et al. Riverine coupling of biogeochemical cycles between land, oceans and atmosphere. Front. Ecol. Environ 9, 53-60 (2011).

6. Hopkinson, C. S. et al. Terrestrial inputs of organic matter to coastal ecosystems: an intercomparison of chemical characteristics and bioavailability. Biogeochemistry 43, 211-234 (1998)

7. Testa, J. M., Kemp, W. M., Hopkinson, C. S. \& Smith, S. V. in Estuarine Ecology 2nd edn (eds Day, J. W., Crump, B. C., Kemp, W. M. \& Yanez-Arancibia, Y.) 381-416 (Wiley, 2013)

8. Hofmann, E. E. et al. Modeling the dynamics of continental shelf carbon. Annu. Rev. Mar. Sci. 3, 93-122 (2011).

9. Mayorga, E. et al. Global nutrient export from WaterSheds 2 (NEWS 2): model development and implementation. Environ. Model. Softw. 25, 837-853 (2010).

10. Dai, M. H., Yin, Z. Q., Meng, F. F., Liu, Q. \& Cai, W. J. Spatial distribution of riverine DOC inputs to the ocean: an updated global synthesis. Curr. Op. Environ. Sustain. 4, 170-178 (2012).

11. Syvitski, J. P. M., Vorosmarty, C. J., Kettner, A. J. \& Green, P. Impact of humans on the flux of terrestrial sediment to the global coastal ocean. Science $\mathbf{3 0 8}$, 376-380 (2005).

12. Hartmann, J, Jansen, N., Durr, H. H., Kempe, S. \& Kohler, P. Global CO consumption by chemical weathering: what is the contribution of highly active weathering regions? Global Planet. Change 69, 185-194 (2009)

13. Meybeck, M. Carbon, nitrogen and phosphorus transport by world rivers. Am. J. Sci. 282, 401-450 (1982)

The first comprehensive summary of terrestrial export of organic and inorganic $\mathrm{C}, \mathrm{N}$ and $\mathrm{P}$ from mostly natural watersheds of the world.

14. Raymond, P. A. et al. Flux and age of dissolved organic carbon exported to the Arctic Ocean: a carbon isotopic study of the five largest arctic rivers. Glob.
Biogeochem. Cycles 21, GB4011 (2007)

15. Beaulieu, E., Godderis, Y., Donnadieu, Y., Labat, D. \& Roelandt, C. High sensitivity of the continental-weathering carbon dioxide sink to future climate change. Nature Clim. Change 2, 346-349 (2012).

16. Laudon, $\mathrm{H}$. et al. Cross-regional prediction of long-term trajectory of stream water DOC response to climate change. Geophys. Res. Lett. 39, L18404 (2012)

17. Hilton, R. G. et al. Tropical-cyclone-driven erosion of the terrestrial biosphere from mountains. Nature Geosci. 1, 759-762 (2008).

18. Yoon, B. \& Raymond, P. A. Dissolved organic matter export from a forested watershed during Hurricane Irene. Geophys. Res. Lett. 39, L18402 (2012).

19. Raymond, P. A. \& Oh, N. H. An empirical study of climatic controls on riverine $C$ export from three major U.S. watersheds. Glob. Biogeochem. Cycles 21, GB2022 (2007).

20. Godsey, S. E., Kirchner, J. W. \& Clow, D. W. Concentration-discharge relationships reflect chemostatic characteristics of US catchments. Hydrol. Processes 23, 1844-1864 (2009).

21. Bianchi, T. S. et al. Enhanced transfer of terrestrially derived carbon to the atmosphere in a flooding event Geophys. Res. Lett 40, 116-122 (2013).

22. Laruelle, G. G. et al. Global multi-scale segmentation of continental and coastal waters from the watersheds to the continental margins. Hydrol. Earth Syst. Sci. 17, 2029-2051 (2013).

23. Bauer, J. E. \& Bianchi, T. S. in Treatise on Estuarine and Coastal Science, Vol. 5 (eds Wolanski, E. \& McLusky, D. S.) 7-67 (Academic, 2011).

24. Bianchi, T. S. \& Bauer, J. E. 2011. in Treatise on Estuarine and Coastal Science, Vol. 5 (eds Wolanski, E. \& McLusky, D. S.) 69-117 (Academic, 2011).

25. Raymond, P. A. \& Bauer, J. E. Use of ${ }^{14} \mathrm{C}$ and ${ }^{13} \mathrm{C}$ natural abundances as a tool for evaluating freshwater, estuarine and coastal organic matter sources and cycling. Org. Geochem. 32, 469-485 (2001)

26. Raymond, P. A. \& Hopkinson, C. S. Jr. Ecosystem modulation of dissolved carbon age in a temperate marsh-dominated estuary. Ecosystems 6, 694-705 (2003).

27. Keil, R. G., Mayer, L. M., Quay, P. E., Richey, J. E. \& Hedges, J. I. Loss of organic matter from riverine particles in deltas. Geochim. Cosmochim. Acta 61, 1507-1511 (1997).

28. Mayer, L. M., Schick, L. L., Skorko, K. \& Boss, E. Photodissolution of particulate organic matter from sediments. Limnol. Oceanogr. 51, 1064-1071 (2006).

29. Moran, M. A., Sheldon, W. M. \& Zepp, R. G. Carbon loss and optical property changes during long-term photochemical and biological degradation of estuarine dissolved organic matter. Limnol. Oceanogr. 45, 1254-1264 (2000).

30. Smith, E. M. \& Benner, R. Photochemical transformations of riverine dissolved organic matter: effects on estuarine bacterial metabolism and nutrient demand. Aquat. Microb. Ecol. 40, 37-50 (2005)

31. Vanderborght, J. P., Wollast, R., Loijens, M. \& Regnier, P. Application of a transport-reaction model to the estimation of biogas fluxes in the Scheldt estuary. Biogeochemistry 59, 207-237 (2002).

32. Sholkovitz, E. R. Flocculation of dissolved organic and inorganic matter during the mixing of river water and seawater. Geochim. Cosmochim. Acta 40, 831-845 (1976).

33. Borges, A. V. \& Abril, G. in Treatise on Estuarine and Coastal Science, Vol. 5 (eds Wolanski, E. \& McLusky, D. S.) 119-161 (Academic, 2011).

This article is a synthesis of the state of our knowledge of the inorganic carbon cycle in coastal waters.

34. Mantoura, R. F. C. \& Woodward, E. Conservative behavior of riverine dissolved organic matter in the Severn estuary. Geochim. Cosmochim. Acta 47,

1293-1309 (1983)

This is the first study to quantitatively assess riverine DOC supply and fate in estuaries using salinity as a conservative tracer and to assess the reactivity of this DOC in ocean carbon budgets.

35. Hopkinson, C. S. \& Vallino, J. J. The relationship between man's activities in watersheds and estuaries: a model of runoff effects on patterns of ecosystem metabolism. Estuaries 18, 598-621 (1995).

36. Howarth, R. et al. Coupled biogeochemical cycles: eutrophication and hypoxia in temperate estuaries and coastal marine ecosystems. Front. Ecol. Environ 9, 18-26 (2011).

37. Hofmann, A. F., Soetaert, K. \& Middelburg, J. J. Present nitrogen and carbon dynamics in the Scheldt estuary using a novel 1-D model. Biogeosciences $\mathbf{5}$, 981-1006 (2008)

38. Frankignoulle, M. et al. Carbon dioxide emission from European estuaries. Science 282, 434-436 (1998).

The first regional synthesis of $\mathrm{CO}_{2}$ emission fluxes from estuaries, demonstrating their importance to regional carbon budgets.

39. Borges, A. V., Delille, B. \& Frankignoulle, M. Budgeting sinks and sources of $\mathrm{CO}_{2}$ in the coastal ocean: diversity of ecosystems counts. Geophys. Res. Lett. 32, L14601 (2005)

40. Laruelle, G. G. \& Dürr, H. H. Slomp, C.P. \& Borges, A.V. Evaluation of sinks and sources of $\mathrm{CO}_{2}$ in the global coastal ocean using a spatially-explicit typology of estuaries and continental shelves. Geophys. Res. Lett. 37, L15607 (2010).

41. Schlesinger, W. H. \& Bernhardt, E. S. Biogeochemistry, An Analysis of Global Change 3rd edn (Academic, 2013)

42. Cai, W.-J. \& Wang, Y. The chemistry, fluxes, and sources of carbon dioxide in the estuarine waters of the Satilla and Altamaha Rivers, Georgia. Limnol. Oceanogr. 43, 657-668 (1998).

43. Raymond, P. A., Caraco, N. F. \& Cole, J. J. Carbon dioxide concentration and atmospheric flux in the Hudson River. Estuaries 20, 381-390 (1997).

44. Cai, W.-J., Wang, Y. C., Krest, J. \& Moore, W. S. The geochemistry of dissolved inorganic carbon in a surficial groundwater aquifer in North Inlet, South Carolina, and the carbon fluxes to the coastal ocean. Geochim. Cosmochim. Acta 67, 631-639 (2003). 
45. Cai, W.-J. Riverine inorganic carbon flux and rate of biological uptake in the Mississippi River plume. Geophys. Res. Lett. 30, 1032 (2003).

46. Zhai, W., Dai, M. \& Guo, X. Carbonate system and $\mathrm{CO}_{2}$ degassing fluxes in the inner estuary of Changjiang (Yangtze) River, China. Mar. Chem. 107, 342-356 (2007).

47. Dittmar, T., Hertkorn, N., Kattner, G. \& Lara, R. Mangroves, a major source of dissolved organic carbon to the oceans. Glob. Biogeochem. Cycles 20, GB1012 (2006).

48. Mcleod, E. et al. A blueprint for blue carbon: toward an improved understanding of the role of vegetated coastal habitats in sequestering $\mathrm{CO}_{2}$. Front. Ecol. Environ. 9, 552-560 (2011).

49. Hopkinson, C. S., Cai, W. J. \& Hu, X. Carbon sequestration in wetland dominated coastal systems - a global sink of rapidly diminishing magnitude. Curr. Op. Environ. Sustain. 4, 1-9 (2012)

50. Mackenzie, F. T., Andersson, A. J., Lerman, A. \& Ver, L. M. in The Sea Vol. 13 (eds Robinson, A. R. \& Brink, K. H) 193-225 (Harvard Univ. Press, 2005).

This is a comprehensive historical description of carbon cycling processes and fluxes through Earth's past, present and future.

51. Jahnke, R. in Carbon and Nutrient Fluxes in Continental Margins (eds Liu, K. K., Atkinson, L., Quinones, R. \& Talaure-McManus, L.) 597-615 (Springer, 2010).

52. Liu, K. K., Atkinson, L., Quinones, R. \& Talaure-McManus, L. Carbon and Nutrient Fluxes in Continental Margins (Springer, 2010).

53. Azetsu-Scott, K. \& Passow, U. Ascending marine particles: significance of transparent exopolymer particles (TEP) in the upper ocean. Limnol. Oceanogr. 49, 741-748 (2004).

54. Blair, N. E. \& Aller, R. C. The fate of terrestrial organic carbon in the marine environment. Annu. Rev. Mar. Sci. 4, 401-423 (2012)

55. Bauer, J. E., Williams, P. M. \& Druffel, E. R. M. ${ }^{14} \mathrm{C}$ activity of dissolved organic carbon fractions in the central North Pacific and Sargasso Sea. Nature 357, 667-670 (1992)

56. Stubbins, A. et al. Illuminated darkness: molecular signatures of Congo River dissolved organic matter and its photochemical alteration as revealed by ultrahigh precision mass spectrometry. Limnol. Oceanogr. 55, 1467-1477 (2010).

57. Hertkorn, N. et al. Characterization of a major refractory component of marine dissolved organic matter. Geochim. Cosmochim. Acta 70, 2990-3010 (2006).

58. Hernes, P. J. \& Benner, R. Photochemical and microbial degradation of dissolved lignin phenols: implications for the fate of terrigenous dissolved organic matter in marine environments. J. Geophys. Res. Oceans 108, 3291 (2003).

59. Bianchi, T. S. The role of terrestrially derived organic carbon in the coastal ocean: A changing paradigm and the priming effect. Proc. Natl Acad. Sci. USA 108, 19473-19481 (2011)

60. Tsunogai, S., Watanabe, S. \& Sato, T. T. Is there a "continental shelf pump" for the absorption of atmospheric $\mathrm{CO}_{2}$ ? Tellus 51B, 701-712 (1999).

61. Cai, W.-J., Dai, M. \& Wang, Y. Air-sea exchange of carbon dioxide in ocean margins: A province-based synthesis. Geophys. Res. Lett. 33, L12603 (2006).

62. Jiang, L.-Q., Cai, W.-J., Wanninkhof, R., Wang, Y. \& Lüger, H. Air-sea $\mathrm{CO}_{2}$ fluxes on the U.S. South Atlantic Bight: spatial and seasonal variability. J. Geophys. Res. 113, C07019 (2008)

63. Walsh, J. J. Importance of continental margins in the marine biogeochemical cycling of carbon and nitrogen. Nature 350, 53-55 (1991).

This is an influential paper summarizing a major US-funded effort, concluding that shelf-break mixing provides a mechanism for $\mathrm{CO}_{2}$ loss from ocean margins.

64. Huang, W.-J., Cai, W.-J., Castelao, R. M., Wang, Y. \& Lohrenz, S. E. Effects of a wind driven cross-shelf large river plume on biological production and $\mathrm{CO}_{2}$ uptake in the Gulf of Mexico during spring. Limnol. Oceanogr. 58, 1727-1735 (2013).

65. Hales, B., Takahashi, T. \& Bandstra, L. Atmospheric $\mathrm{CO}_{2}$ uptake by a coastal upwelling system. Glob. Biogeochem. Cycles 19, GB1009 (2005).

66. Chen, C.-T. A., Huang, T.-H., Chen, Y.-C., Bai, Y., He, X., \& Kang, Y. Air-sea exchanges of $\mathrm{CO}_{2}$ in world's coastal seas. Biogeosciences 10, 5041-5105 (2013).

67. Bates, N. R. Moran, S. B., Hansell, D. A. \& Mathis, J. T. An increasing $\mathrm{CO}_{2}$ sink in the Arctic Ocean due to sea-ice loss. Geophys. Res. Lett. 33, L23609 (2006).

68. Smith, S. V. \& Hollibaugh, J. T. Coastal metabolism and the oceanic carbon balance. Rev. Geophys. 31, 75-89 (1993).

One of the first papers to show that coastal oceans are net heterotrophic due to respiration enhanced by exported terrestrial oceanic carbon.

69. Mackenzie, F. T., Lerman, A. \& Andersson, A. J. Past and present of sediment and carbon biogeochemical cycling models. Biogeosciences 1, 11-32 (2004).

70. del Giorgio, P. A. \& Williams, P. J. Respiration in Aquatic Ecosystems (Oxford Univ. Press, 2005).

71. Le Quéré et al. The global carbon budget 1959-2011. Earth Syst. Sci. Data 5, 165-185 (2013).

72. Stallard, R. F. Terrestrial sedimentation and the carbon cycle: Coupling weathering and erosion to carbon burial. Glob. Biogeochem. Cycles 12, 231-257 (1998).

73. Smith, S. V., Renwick, W. H., Buddemeier, R. W. \& Crossland, C. J. Budgets of soil erosion and deposition for sediments and sedimentary organic carbon across the conterminous United States. Glob. Biogeochem. Cycles 15, 697-707 (2001).

74. Raymond, P. A., Oh, N. H., Turner, R. E. \& Broussard, W. Anthropogenically enhanced fluxes of water and carbon from the Mississippi River. Nature $\mathbf{4 5 1}$ 449-452 (2008).

75. Wilson, H. F. \& Xenopoulos, M. A. Effects of agricultural land use on the composition of fluvial dissolved organic matter. Nature Geosci. 2, 37-41 (2009).
76. Raymond, P. A. et al. Controls on the variability of organic matter and dissolved inorganic carbon ages in northeast US rivers. Mar. Chem. 92, 353-366 (2004).

77. Moore, S. et al. Deep instability of deforested tropical peatlands revealed by fluvial organic carbon fluxes. Nature 493, 660-663 (2013).

78. Monteith, D. T. et al. Dissolved organic carbon trends resulting from changes in atmospheric deposition chemistry. Nature 450, 537-540 (2007).

79. Calmels, D., Gaillardet, J., Brenot, A. \& France-Lanord, C. Sustained sulfide oxidation by physical erosion processes in the Mackenzie River basin: climatic perspectives. Geology 35, 1003-1006 (2007).

80. Cai, W.-J. et al. Acidification of subsurface coastal waters enhanced by eutrophication. Nature Geosci. 4, 766-770 (2011).

81. Doney, S. C. The growing human footprint on coastal and open-ocean biogeochemistry. Science 328, 1512-1516 (2010)

A paper describing the close coupling between land and ocean systems and the importance of anthropogenic impacts on coastal and open ocean systems

82. Dai, M. et al. Oxygen depletion in the upper reach of the Pearl River estuary during a very drought winter. Mar. Chem. 102, 159-169 (2006)

83. Scavia, D. et al. Climate change impacts on U.S. coastal and marine ecosystems. Estuaries 25, 149-164 (2002)

84. Stedmon, C. A., Amon, R. M. W., Rinehart, A. J. \& Walker, S. A. The supply and characteristics of colored dissolved organic matter (CDOM) in the Arctic Ocean: pan Arctic trends and differences. Mar. Chem. 124, 108-118(2011)

85. Diaz, R. J. \& Rosenberg, R. Spreading dead zones and consequences for marine ecosystems. Science 321, 926-929 (2008).

86. Duarte, C. M., Middelburg, J. \& Caraco, N. Major role of marine vegetation on the oceanic carbon cycle. Biogeosciences 2, 1-8 (2005).

This paper describes a multifaceted approach to quantifying the carbon fixed by estuarine macrophytes and its relevance to organic carbon sequestration in coastal sediments and heterotrophy in adjacent coastal systems.

87. Cai, W.-J., Wang, Z. H. A. \& Wang, Y. C. The role of marsh-dominated heterotrophic continental margins in transport of $\mathrm{CO}_{2}$ between the atmosphere, the land-sea interface and the ocean. Geophys. Res. Lett. 30, 1849 (2003).

88. Andersson, A. J., Mackenzie, F. T. \& Lerman, A. Coastal ocean and carbonate systems in the high $\mathrm{CO}_{2}$ world of the Anthropocene. Am. J. Sci. 305, 875-918 (2005).

89. Krumins, V., Gehlen, M., Arndt, S., Van Cappellen, P. \& Regnier, P. Dissolved inorganic carbon and alkalinity fluxes from coastal marine sediments: model estimates for different shelf environments and sensitivity to global change. Biogeosciences 10, 371-398 (2013)

90. Bianchi, T. S. \& Canuel, E. A. Chemical Biomarkers in Aquatic Ecosystems (Princeton Univ. Press, 2011).

91. Ingalls, A. E. \& Pearson, A. Ten years of compound-specific radiocarbon analysis. Oceanography 18, 18-31 (2005).

92. Mopper, K., Stubbins, A., Ritchie, J. D., Bialk, H. M. \& Hatcher, P. G. Advanced instrumental approaches for characterization of marine dissolved organic matter: extraction techniques, mass spectrometry, and nuclear magnetic resonance spectroscopy. Chem. Rev. 107, 419-442 (2007).

93. Kujawinski, E. B. The impact of microbial metabolism on marine dissolved organic matter. Annu. Rev. Mar. Sci. 3, 567-599 (2011).

94. Seitzinger, S. P. \& Giblin, A. E. Estimating denitrification in North Atlantic continental shelf sediments. Biogeochemistry 35, 235-260 (1996).

95. Collins, W. J. et al. Development and evaluation of an Earth-system modelHadGEM2. Geosci. Model Dev. 4, 1051-1075 (2011)

96. da Cunha, L. C., Buitenhuis, E. T., Le Quéré, C., Giraud, X. \& Ludwig, W. Potential impact of changes in river nutrient supply on global ocean biogeochemistry. Glob. Biogeochem. Cycles 21, GB4007 (2007).

97. Bernard, C., Dürr, H., Heinze, C., Segschneider, J. \& Maier-Reimer, E. Contribution of riverine nutrients to the silicon biogeochemistry of the global ocean - a mode study. Biogeosciences 8, 551-564 (2011).

98. Lachkar, Z. \& Gruber, N. What controls biological productivity in coastal upwelling systems? Insights from a comparative modeling study. Biogeosciences 8, 5617-5652 (2011)

99. Chen, R. F., Fry, B., Hopkinson, C. S., Repeta, D. J. \& Peltzer, E. T. Dissolved organic carbon on Georges Bank. Cont. Shelf Res. 16, 409-420 (1996).

100. Hopkinson, C. S. \& Vallino, J. J. Efficient export of carbon to the deep ocean through dissolved organic carbon. Nature 433, 142-145 (2005).

Acknowledgements This work was supported in part by the National Science Foundation's Chemical and Biological Oceanography, Integrated Carbon Cycle Research, Arctic Natural Sciences, Long-Term Ecological Research, and Ecosystem Ecology programs; NASA Interdisciplinary Research in Earth Science program NOAA; Georgia Sea Grant; the European Union's Seventh Framework Program project GEOCARBON; and the government of the Brussels-Capital Region. We acknowledge our late friend and colleague Y. Wang, whose contributions to coastal carbon cycle research and $\mathrm{CO}_{2}$ measurement technology have significantly advanced the field. We also thank A. Grottoli for comments and discussion on an earlier version of this manuscript.

Author Information Reprints and permissions information is available at www.nature.com/reprints. The authors declare no competing financial interests. Readers are welcome to comment on the online version of this article at www.nature.com/fir3il. Correspondence should be addressed to J.E.B. (bauer.362@osu.edu). 